\title{
Simulation, Validation and Economic Analysis of Solar Powered Organic Rankine Cycle for Electricity Generation
}

\author{
Suresh Baral and Kyung Chun Kim
}

\begin{abstract}
This paper presents the efficiencies such as exergy, thermal, solar power cycle efficiency, along with solar heat input and area of the solar collector for 4 selected working fluids. Thermodynamic modeling was carried out using a commercial scroll expander, two compact heat exchangers, a diaphragm pump and a solar collector. The commercial software Engineering Equation Solver (EES) was used for calculating the parameters of various working fluids. The analyzed working fluids have been recommended for solar ORC. Furthermore, the economic analysis of solar powered ORC system has been carried out with the solar collector cost and the overall ORC cost of each working fluid in the system. Finally the payback period has been calculated and was around 3.7 years.
\end{abstract}

Index Terms-Economic analysis, organic Rankine cycle, solar collector, thermal efficiency.

\section{INTRODUCTION}

Organic Rankine cycle (ORC) has been the best proven technology for energy conversion for harnessing energy from low-temperature heat source. The ORC systems are exploited in variety of energy resources such as solar, geothermal, biomass and waste heat energy. The size of the ORC plant ranges from few kilowatts to big size megawatts plants. These days more researches have been carried out in focusing solar energy conversion into electricity. Though there are few drawbacks for solar powered ORC system such as high investment costs, large area requirement for installation, highly dependent on the weather conditions, less efficiency, poor performance characteristics and un-matured technology but still it is useful for reduction in consumption of fossil fuel to reach the energy sustainability. However, small sizes ORCs can be widely used in various applications such as electricity generation in remotes houses, domestic CHP units or thermally driven heat pumps. Currently, 1.6 billion people all around the world still have no access to electricity. Huge communities in underdeveloped countries do not have a centralized grid connected to their main lines of electricity [1]. Therefore, conversion techniques from low heat source to electricity in the underdeveloped countries, which require rural electrification, are needed. In this context, the present paper is divided into two parts. The first part deals with the

Manuscript received November 25, 2013; revised January 15, 2014. This work was supported by the Energy Efficiency and Resources Core Technology Program of the Korea Institute of Energy Technology Evaluation and Planning (KETEP) granted financial resources from the Ministry of Trade, Industry and Energy, Republic of Korea (No. 20112010100030).

Suresh Baral and K. C. Kim are with the School of Mechanical Engineering, Pusan National University, Busan 609-735, Republic of Korea (e-mail: baral@pusan.ac.kr, kckim@pusan.ac.kr). working fluid selection, simulation and validation of the results and final part discusses the economic analysis of solar based ORC system for $1 \mathrm{~kW}$ electric power. The simulation work presented in this paper was carried out with the commercial software Engineering Equation Solver (EES). The basic fundamental laws of thermodynamics have been incorporated and the thermodynamic parameters were calculated. The organic working fluids selection for solar powered Rankine cycle plays important role in overall efficiencies of the system. Various authors [2]-[5] screened various pure organic compounds for using as working fluids in ORC system and predicts the thermo-physical behavior of working fluids depending on critical temperature, normal boiling temperature and pressure. The solar ORC system can work with saturated vapour or with a constant superheating of a few degrees Celsius depending on the fluid properties. In this study the introduction of the super heater is avoided for minimizing the cost of the system. Furthermore the working fluid compounds should also meet the Montreal Protocol and Kyto Protocol agreement [6]-[8]. For the simulation model only few pure working fluids compounds are selected for solar ORC application which can be listed in Table I.

TABLE I: PROPERTIES OF WORKING FLUIDS [6]

\begin{tabular}{ccccccc}
\hline \hline Fluid & $\begin{array}{c}\text { Crit } \\
\text { Temp } \\
\left({ }^{\circ} \mathrm{C}\right)\end{array}$ & $\begin{array}{c}\text { Crit } \\
\text { Press } \\
(\mathrm{MPa})\end{array}$ & $\begin{array}{c}\text { ASHRAE } \\
\text { group }\end{array}$ & $\begin{array}{c}\text { Atm. life } \\
\text { time(yr) }\end{array}$ & ODP & $\begin{array}{c}\text { GWP } \\
100 \\
\text { yrs }\end{array}$ \\
\hline R245fa & 154.2 & 3.64 & B1 & 8.8 & 0 & 820 \\
R123 & 183.7 & 3.668 & B1 & 1.3 & 0.02 & 77 \\
R141b & 204.2 & 4.25 & n.a & 9.3 & 0.12 & 725 \\
$\begin{array}{c}\text { Ethano } \\
1\end{array}$ & 240.8 & 6.14 & n.a & n.a & n.a & n.a \\
\hline \hline
\end{tabular}

\section{SOLAR ORC SYSTEM MODELING}

The present solar ORC system consisted of a working fluid pump (diaphragm type), two compact heat exchangers and a commercial scroll expander, as shown in Fig. 1. The working principle is explained as the hot water obtained by the solar collector is passed through the evaporator. The ORC working fluid is pumped and passed through the evaporator, where it changes its phase. The working fluid at the turbine outlet is condensed in the condenser by cold water supplied from a tap and flows back into the circulation pump to begin a repeated cycle.

A simulation and thermodynamic modeling of the present system was carried out to predict the performance characteristics of the solar organic Rankine cycle under a 
range of conditions and parameters. The system equations were derived easily from the energy and mass balance for a control volume. The exergy of the ORC system was calculated using the enthalpy and entropy of the evaporator inlet and the dead state. The system equations obtained can be expressed as follows:

$$
\begin{gathered}
\text { Evaporator: } Q_{i n}=h_{4}-h_{1} \\
\text { Condenser: } Q_{\text {out }}=h_{3}-h_{2} \\
\text { Turbine: } W_{t}=\dot{m}\left(h_{1}-h_{2 s}\right) \eta_{t} \\
\text { Pump: } W_{p}=\dot{m}\left(h_{3}-h_{4 s}\right) / \eta_{p} \\
\text { Power output, } \mathrm{W}_{\text {out }}: \dot{m}\left(h_{1}-h_{2 s}\right) \eta_{t}-m\left(h_{3}-h_{4 s}\right) / \eta_{p} \\
\text { Thermal efficiency: } \eta_{O R C}=\frac{W_{\text {out }}}{Q_{i n}} \\
\text { Solar power cycle efficiency: } \eta_{S P C}=\eta_{t h} \times \eta_{c} \\
\text { Exergy state point: } E_{i}=\dot{m}\left[\left(h_{i}-h_{o}\right)-T_{o}\left(s_{i}-s_{o}\right)\right] \\
\text { Exergy efficiency: } \eta_{e x g}=W_{n e t} / \dot{E}_{i} \\
\text { Area of collector: } \mathrm{A}_{\mathrm{c}}=Q_{i n} /\left(\eta_{c} \times I \times W_{n e t}\right)
\end{gathered}
$$

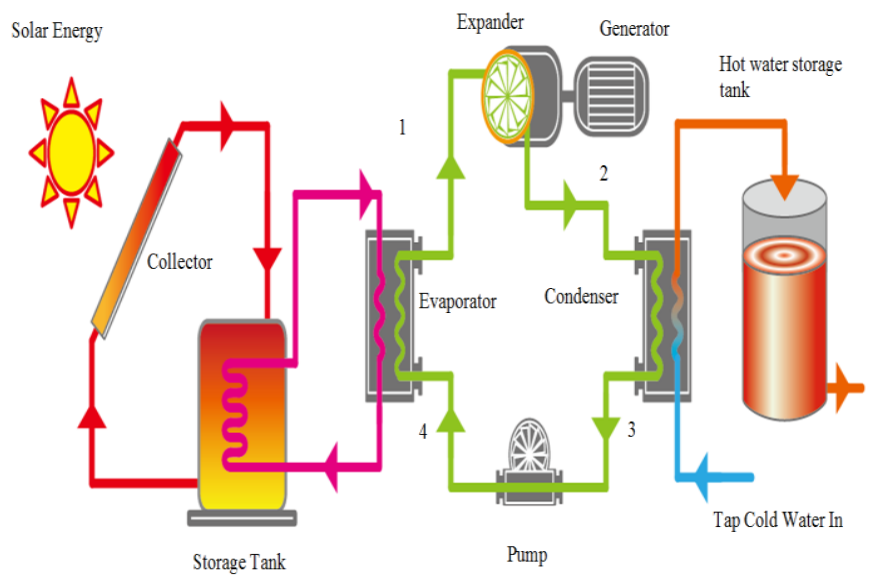

Fig. 1. Schematic diagram of solar ORC.

The present work also compared several ORC working fluids for system efficiencies, appropriate area of the solar collector for $1 \mathrm{~kW}$ power output.

For simplicity, several reasonable assumptions were implemented by thermodynamic modeling. The assumptions are listed as follows:

1) The electric power at the expander is fixed at $1 \mathrm{~kW}$.

2) The evaporating temperature for solar ORC ranges from $100{ }^{\circ} \mathrm{C}$ to $150{ }^{\circ} \mathrm{C}$.

3) The condensation temperature is fixed to $25^{\circ} \mathrm{C}$.

4) The efficiency of the expander is set to be $70 \%$.

5) The efficiency of the pump is assumed to be $70 \%$.

6) The solar collector efficiency is presumed to be $70 \%$.

7) The internal irreversibility is ignored.

8) The pressure drops in the components other than the expander are ignored.

\section{RESUlTS AND DisCUSSIONS}

In total, 4 pure organic working fluids were selected as potential candidates as shown in Table I. The Table II lists the system performance results for a design of $1 \mathrm{~kW}$ power output.

\begin{tabular}{cccccccc}
\multicolumn{1}{c}{ TABLE II: SYSTEM PERFORMANCE FOR A 1 KW POWER OUTPUT ORC } \\
\hline \hline Working & $\mathrm{P}_{\max }$ & $\eta_{\text {exg }}$ & $\eta_{\text {th }}$ & $\eta_{\mathrm{SPC}}$ & $\dot{V}$ & $\mathrm{~A}_{\mathrm{c}}$ & $\begin{array}{c}\mathrm{Q}_{\text {in }} \\
\text { Fluid }\end{array}$ \\
& $(\mathrm{kPa})$ & $(\%)$ & $(\%)$ & $(\%)$ & $(\mathrm{L} / \mathrm{s})$ & $\left(\mathrm{m}^{2}\right)$ & $(\mathrm{kW})$ \\
\hline $\mathrm{R} 245 \mathrm{fa}$ & 3379 & 46 & 14 & 10 & 0.08 & 12.21 & 6.84 \\
$\mathrm{R} 123$ & 2104 & 55 & 17 & 12 & 0.15 & 10.28 & 5.75 \\
$\mathrm{R} 141 \mathrm{~b}$ & 1791 & 52 & 16 & 11 & 0.23 & 10.85 & 6.07 \\
Ethanol & 980 & 55 & 17 & 12 & 0.3 & 10.19 & 5.7 \\
\hline \hline
\end{tabular}

\section{A. Efficiencies}

The ORC efficiency is the most important index used to evaluate the performance of the system. The exergy efficiency is an indicator of how close the thermal efficiency is to the highest value permissible depending on the temperature range (Carnot efficiency). The system exergy efficiency ranged from $46 \%$ to $55 \%$ in this simulation model. The maximum exergy efficiency was obtained using R123 and Ethanol as shown in Table II. This is because these fluids rise at low working pressures as the enthalpy difference in the expander increases. Lower exergy efficiency means higher system irreversibility. Normally, in an ORC system, the evaporator makes the largest contribution to the overall irreversibility followed by the expander. R245fa has the lowest exergy efficiency fluid, requires the largest heat input due to the large irreversibility in the evaporator.

The thermal efficiency and solar power cycle efficiency ranged from $14 \%$ to $17 \%$ and $10 \%$ to $12 \%$, respectively. From Fig. 2 the overall solar power efficiency of ORC changes with increase in turbine inlet temperature. So it is always necessary to run solar ORC in its full turbine inlet temperature rating for getting the highest efficiency of the system. The solar efficiency depends on the characteristics of solar collector also. The solar collectors may be different types such as flat plate, heat pipe vacuum type and parabolic type of collectors.

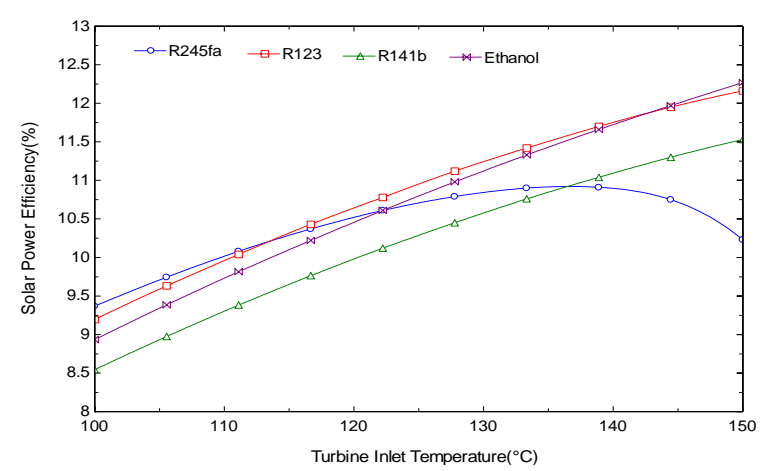

Fig. 2. Variation in solar power efficiency with turbine inlet temperature.

\section{B. Operating Pressure and Volume Flow Rates}

To obtain the optimum efficiency of system there should be certain range of operating pressure for various working fluids with their thermal-physical behavior when subjected with certain temperature. The operating pressure is determined from the design conditions of ORC. The pressure needed for operating ORC also determines the cost of the system. The 
higher is the operating pressure, the larger is the need of heat exchanger. From Table II, it can be been seen that R245fa has the highest operating pressure needed followed by R123, $\mathrm{R} 141 \mathrm{~b}$ and Ethanol. The high operating pressure needs robust expander for withstanding its desired pressure. The other way is by dividing the pressure by installing the expanders in series or in parallel. This is advantageous because the system power output is highest but on other hand the ORC system will be quite expensive because of increased number of expanders. The expander in the ORC system is one of the expensive components. From Fig. 3, it is also revealed that $\mathrm{R} 245 \mathrm{fa}$ has wide range of operating pressure for $100{ }^{\circ} \mathrm{C}$ to $150{ }^{\circ} \mathrm{C}$ turbine inlet pressure. The pressure of $1260 \mathrm{kPa}$ to $3380 \mathrm{kPa}$ falls under the operating pressure of R245fa while others have short operating range of pressure from $200 \mathrm{kPa}$ to $2100 \mathrm{kPa}$. From the simulation procedure for working fluids selection, the thermal efficiency should also be accounted because it changes with the inlet turbine pressure.

From economical point of view, the turbine outlet volume flow rate plays an important role because it determines the size and cost. As shown in Table II, R245fa and R123 have quiet low flow rates. These low volume flow rates are preferable for decreasing the pump size and friction loss in a pipe system. In general, the turbine outlet volume flow rate is inversely proportional to the turbine inlet temperature, which can be illustrated in Fig. 4. The proper introduction of a working fluid mass flow rate is necessary for the expansion process. The pump selection is also another fundamental aspect for appropriate mass flow rate pumping. For the economic condition ethanol is feasible for a large capacity ORC system for electric power generation using solar energy. Low volume flow rates are also important aspect for choice of working fluid in the system in terms of monetary value. Generally the R245fa is quite expensive as compared to other working fluids.

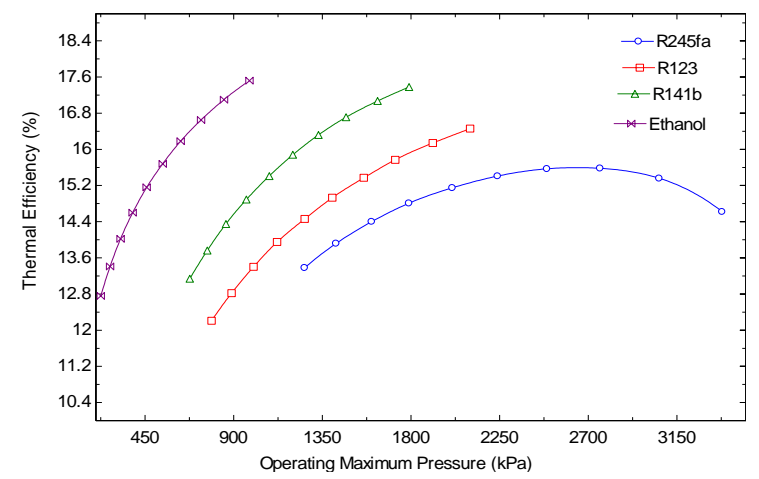

Fig. 3. Variation in thermal power efficiency with turbine inlet pressure ranges.

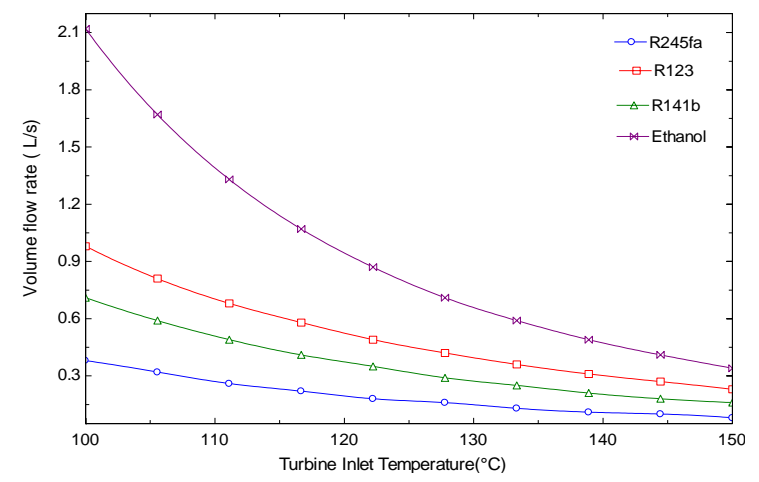

Fig. 4. Volume flow rate versus turbine inlet temperature.

\section{Required Heat Input and Solar Collector Area}

The heat input to the system is significant in a solar ORC that determines the size of the collector and establishes a major part of the system cost. Therefore, solar applications will be more viable with fluids for which the amount of heat required is small. From Table II, the heat required for a $1 \mathrm{~kW}$ power output falls in the range between $5-7 \mathrm{~kW}$ when the inlet turbine temperature is fixed at $150{ }^{\circ} \mathrm{C}$. Fig. 5 shows the heat input needed will be less if the inlet turbine temperature changes from lower to highest.

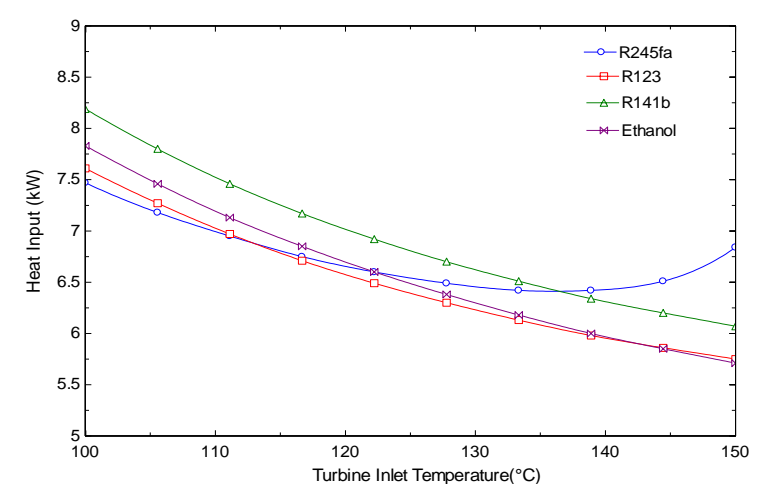

Fig. 5. Variation in heat input with turbine inlet temperature.

The area of solar collector in ORC system is determined by the heat input, net work done and solar insolation of the location for installation. From Fig. 6 it can be seen that the area of collector is fully depended on the solar insolation of the location where the plant is installed. If the solar radiation is too high in the particular location then the needed area is too less and is far more cheap for installation and getting of profit in very short period of establishment. From Table II, the large area needed is for R245fa and the smallest is for Ethanol whose areas are $12.21 \mathrm{~m}^{2}$ and $10.19 \mathrm{~m}^{2}$ respectively. For a 1 $\mathrm{kW}$ power output, the required area of the collector is in the range, $10-13 \mathrm{~m}^{2}$. The collector area also constitutes a major part of the system cost.

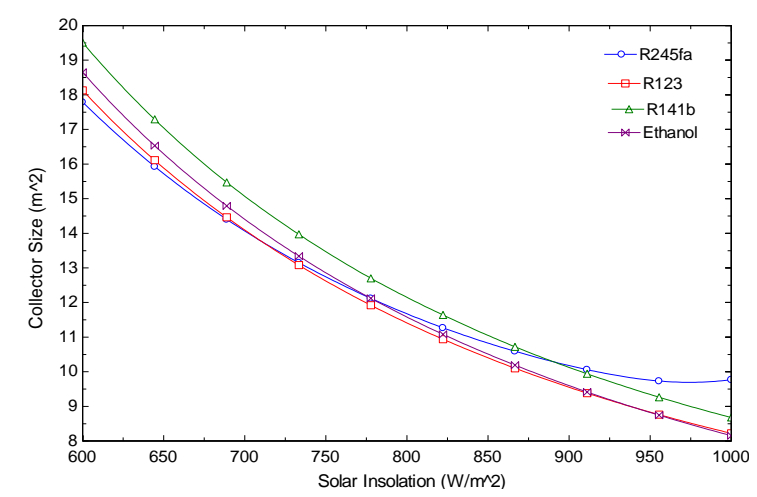

Fig. 6. Collector size versus solar insolation.

\section{VERIFICATION AND VALIDATION}

For the verification and validation of simulation model the results were compared with the experimented data. The experimental data were obtained from a small scale ORC system using a scroll expander developed in our laboratory [9]. The ORC system used R245fa as the working fluid. The experiment was carried out with the evaporating pressure of $2520 \mathrm{kPa}$ and condensing temperature of $45^{\circ} \mathrm{C}$. The 
experiment was carried out with the setting mass flow at different rates. The heat source was hot water generated by an electric heater whose temperature was $130^{\circ} \mathrm{C}$ [9]. The expander used in this experiment was locally manufactured. The large size exchanger was used and condenser used chiller for cooling of vapor after expansion. The $10 \mathrm{~kW}$ size of ORC using hot water as heat source was used for generating of electric power. Fig. 7 shows the simulated results and experimental data plotted for comparison. In general, both results agree well within the uncertainty range of experiment. However, the simulated efficiency is slightly higher than that of the experiment. It can be explained that the internal losses of the real piping system and heat exchanger pressure losses are not taken into accounted in the system while carrying out the simulation. The other reason attributed to the expander's efficiency being fixed for whole calculation. In real case, the expander's efficiency is not always constant. Additionally, there occurs irreversibility in the system. The trend of the simulated ORC system thermal efficiency versus working fluid mass flow rate shows a good agreement with the experimental data. The average deviation between experiment and simulation is $3.5 \%$ while the maximum deviation is $4.5 \%$ in correspondence of the higher values of working fluid mass flow rate. Moreover, it can be observed that ORC system efficiency values are in the range $5 \%-8 \%$, in agreement with literature data for ORC systems characterized by a net electric power output in order of few $\mathrm{kW}$. The experimental and simulated thermal efficiency follow the same behavior, even though the simulation model has few assumptions as discussed earlier. Furthermore, it was revealed that the increase in working fluid mass flow rate resulted in higher thermal efficiency and shaft power output. Though the simulation model can predict within the small range of deviation, it seems that the model works well for other working fluids also.

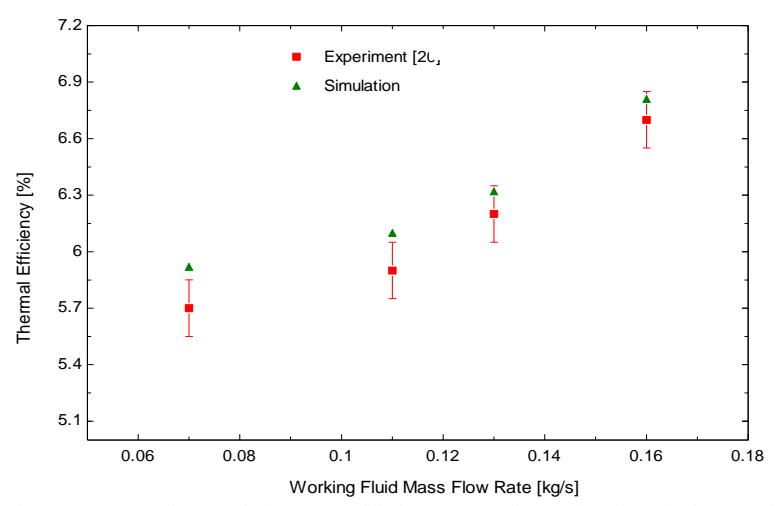

Fig. 7. Comparison of thermal efficiency predicted by simulation and experimental data obtained in a small scale ORC system [9] for the validation of mathematical models.

\section{ECONOMIC ANALYSIS}

The goal of this section is to propose an economic analysis for the solar powered ORC for electricity generation. The total investment and operation and management costs analyses are performed for $1 \mathrm{~kW}$ power ORC. For calculating of cost of the ORC plants, each components cost are obtained from the already purchased invoice in our laboratory. Different components such as scroll expander, brazed plate heat exchanger, pumps and solar collectors are considered as main items which occupies huge percentage of price share in the solar ORC power plant [10]. The remaining piping, frame and fitting, working fluids and other are considered as secondary price sharing components. Table III shows the main components required for solar powered ORC.

For the cost analysis we considered that the price of working fluids and solar collectors as variables. Since the area of collector changes with solar insolation and the type of working fluids also greatly influence the cost in the total ORC plant. Normally the working fluids which have some limitations due to environmental consequences, the price is quite high and the one which is widely available and commercially easy to manufacture is cheaper working fluids such as ethanol. In this section the cost analysis is carried out on the basis of research prototype in the academic. Table IV shows the cost of components along with other working fluids.

TABLE III: COMPONENTS FOR SOLAR-POWERED ORC

\begin{tabular}{cccc}
\hline \hline Component & Model & Description & Unit \\
\hline $\begin{array}{c}\text { Solar } \\
\text { Collectors } \\
\text { Scroll } \\
\text { Expander }\end{array}$ & EP-10 & Apack Inc. & 8 \\
Evaporator & CB60-14H-F & AlfaLaval & 1 \\
Condenser & CB76-50E & AlfaLaval & 1 \\
$\begin{array}{c}\text { Plunger type } \\
\text { Pump }\end{array}$ & CAT & CAT & 1 \\
Working & Plumps & Pumps & 10 \\
\hline \hline
\end{tabular}

TABLE IV: APPROXIMATE COST FOR SOLAR ORC SYSTEM

\begin{tabular}{lllll}
\hline \hline Fluid & R245fa & R123 & R141a & Ethanol \\
\hline Solar Collectors(\$) & 4700 & 4900 & 4500 & 4600 \\
Scroll Expander(\$) & 3900 & 3900 & 3900 & 3900 \\
Heat exchangers(\$) & 2000 & 2000 & 2000 & 2000 \\
Plunger Pump(\$) & 1500 & 1500 & 1500 & 1500 \\
Piping(\$) & 1000 & 1000 & 1000 & 1000 \\
Frame \& Fittings(\$) & 1000 & 1000 & 1000 & 1000 \\
Load Bank(\$) & 500 & 500 & 500 & 500 \\
Measuring Devices(\$) & 2500 & 2500 & 2500 & 2500 \\
Working Fluid(\$) & 1500 & 4000 & 2000 & 1000 \\
Storage Tank(\$) & 1000 & 1000 & 1000 & 1000 \\
Grand Total $(\$)$ & 19600 & 22300 & 19900 & 19000 \\
\hline \hline
\end{tabular}

The approximate cost of solar ORC system for $1 \mathrm{~kW}$ power output is around $\$ 19000$ to $\$ 22000$. The cost of small size ORC system is huge as compared to large size ORC. The working fluid R123 is expensive because it has environmental threats but the efficiency and the power obtained is maximum. The ORC having working fluid of ethanol is a bit cheaper than other because it can be easily manufactured. The cost of solar collector is influence by the inlet temperature of the turbine. Higher the temperature the lower is the cost. R245fa shows less cost compared to others. The cost is cheaper if the temperature is in between $120^{\circ} \mathrm{C}$ and $140^{\circ} \mathrm{C}$. The temperature plays important role because the high thermal energy can be obtained from the higher temperature. This high thermal energy is determines the size of collector to be installed for operating of ORC system. Different types of collectors such as flat, vacuum and parabolic collectors are generally used for 
getting the temperature within the desired need of ORC performance and conditions. The Fig. 8 shows the variation in the cost due to the variation on the temperature of inlet of turbine. In other words the inlet turbine temperature can be obtained from the different solar collector as highlighted above. Another prospective for solar collector cost variation is due to the meteorology conditions. The four seasons all year shows different pattern but there is not too much deviation in the price of solar collector cost. Fig. 9 shows the cost of collector for each fluid when subjected to change in solar insolation. The minimum solar insolation in this present paper is assumed to be $600 \mathrm{~W} / \mathrm{m}^{2}$ and the maximum is to be $1000 \mathrm{~W} / \mathrm{m}^{2}$.

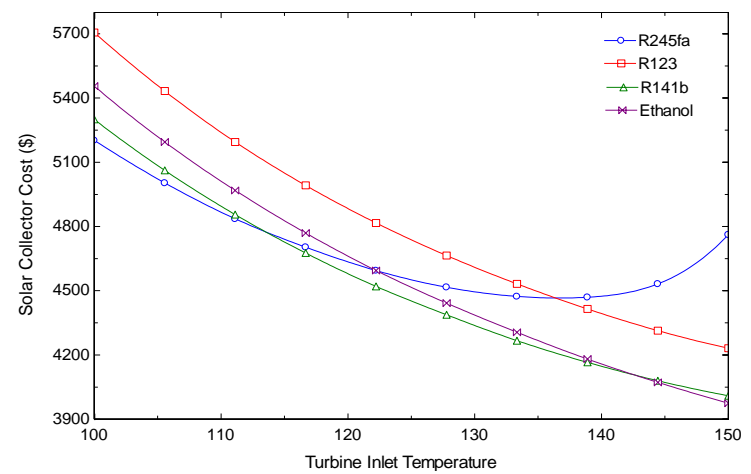

Fig. 8. Collector cost variation with turbine inlet temperature.

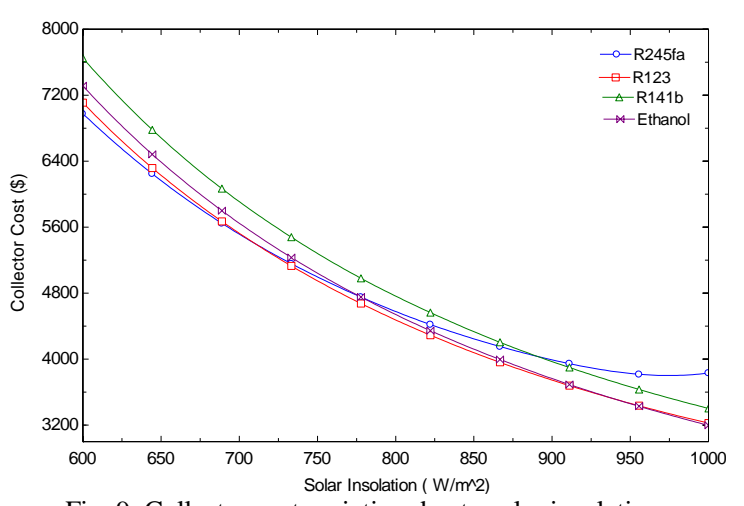

Fig. 9. Collector cost variation due to solar insolation.

\section{A. Payback Period}

The payback period of the solar ORC is determined by the annual income generation from the power obtained through the system. In other words, it is the time required to get back the money spent in the solar ORC system.

Payback period $=$ Total cost invested $/$ Revenue generated

For simplicity the following are the assumptions for calculating the payback period.

1) The sunshine during is assumed to be 5 hours only per day.

2) The average solar insolation in the particular location is assumed to be $800 \mathrm{~W} / \mathrm{m}^{2}$.

3) The collector efficiency is presumed to be $70 \%$. (Best case scenario).

4) No any insurance, tax and subsidy are considered.

5) The cost of electricity (kWh) is assumed to be $\$ 0.39$.

Table V shows the revenue generated during the year and the payback period for each fluid. It can be seen that the solar ORC capital cost will be recovered with the 3.7 years. The most economical solar ORC are the working fluids with $\mathrm{R} 141 \mathrm{~b}$ and R245fa. Since the payback period is almost same for each working fluid but if more cost changing variables such as size of heat exchanger, the size of expander and the pump are taken into consideration then the period changes automatically. In large scale of electrical generation, the recommended working fluid is R245fa in solar ORC.

\begin{tabular}{|c|c|c|c|}
\hline Fluid & $\begin{array}{l}\text { Electricity } \\
(\mathrm{kWh}) / \text { year }\end{array}$ & $\begin{array}{c}\text { Revenue } \\
(\$)\end{array}$ & $\begin{array}{r}\text { Payback } \\
\text { period } \\
\text { (year) }\end{array}$ \\
\hline R245fa & 13447 & 5244.33 & 3.74 \\
\hline R123 & 14747 & 5751.33 & 3.88 \\
\hline R141b & 13699 & 5342.61 & 3.72 \\
\hline Ethanol & 12662 & 4938.18 & 3.85 \\
\hline
\end{tabular}

\section{CONCLUSION}

A $1 \mathrm{~kW}$ solar organic Rankine cycle system was studied and modeled thermodynamically with 4 selected organic working fluids for temperature ranging from $100^{\circ} \mathrm{C}$ to $150^{\circ} \mathrm{C}$. The analysis involved comparing various parameters, such as exergy, thermal, solar power cycle efficiencies in addition to the heat input, turbine inlet volume flow rate, and the required area of solar collector. For verification of the simulation model, the experimental data were compared with the simulated one. In the second part of the paper the economic analysis was carried out. The analysis showed that the payback period of the solar ORC system is around 3.7 years. The total cost of research prototype testing facility of solar based ORC system is not more than $\$ 20000$. Finally from the various range of parameters the working fluid $\mathrm{R} 245 \mathrm{fa}$ is considered the best candidate for using in solar powered ORC in generating electric power.

\section{REFERENCES}

[1] S. Quoilin, M. Orosz, H. Hemond, and V. Lemort, "Performance and design optimization of a low-cost solar organic Rankin cycle for remote power generation," Solar Energy, vol. 85, pp. 955-966, 2011.

[2] B. F. Tchanche, G. Lambrinos, A. Frangoudakis, and G. Papadakis, "Low-grade heat conversion into power using organic Rankine cycles-A review of various applications," Renewable and Sustainable Energy Reviews, vol. 15, no. 8, pp. 3963-3979, 2011.

[3] T. C. Hung, T. Y. Shai, and S. K. Wang, "A review of organic Rankine cycles (ORCs) for the recovery of low-grade waste heat," Energy, vol. 22, no. 7, pp. 661-667, 1997.

[4] H. J. Chen, D. Y. Goswami, and E. K. Stefanakos, "A review of thermodynamic cycles and working fluids for the conversion of low-grade heat," Renewable and Sustainable Energy Reviews, vol. 14, no. 9, pp. 3059-3067, 2010.

[5] U. Drescher, and D. Brüggemann, "Fluid selection for the Organic Rankine Cycle (ORC) in biomass power and heat plants," Applied Thermal Engineering, vol. 27, no. 1, pp. 223-228, 2007.

[6] J. Li, P. Gang, and J. Jie, "Optimization of low temperature solar thermal electric generation with organic Rankine cycle in different areas," Applied Energy, vol. 87, no. 11, pp. 3355-3365, 2010.

[7] D. H. Wei, X. S. Lu, L. Zhen, and J. M. Gu, "Performance analysis and optimization of organic Rankine cycle (ORC) for waste heat recovery," Energy conversion and Management, vol. 48, no. 4, pp 1113-1119, 2007.

[8] A. M. Delgado-Torres and L. García-Rodríguez, "Analysis and optimization of the low-temperature solar organic Rankine cycle (ORC)," Energy Conversion and Management, vol. 51, no. 12, pp. 2846-2856, 2010.

[9] E. Yun, H. D. Kim, S. Y. Yoon, and K. C. Kim, "Development and characterization of small-scale ORC system using scroll expander," Applied Mechanics and Materials, vol. 291-294, pp. 1627-1630, 2013. 
[10] M. Q. Li, J. F. Wang, S. L. Li, X. R. Wang, W. F. He, and Y. P. Dai, "Thermo-economic analysis and comparison of a $\mathrm{CO}_{2}$ transcritical power cycle and an organic Rankine cycle," Geothermics, vol. 50, pp. $101-111,2014$

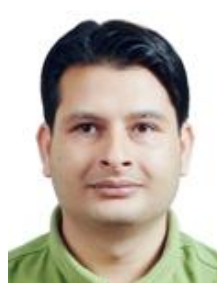

Suresh Baral is a PhD student in the School of Mechanical Engineering, Pusan National University, South Korea. His advisor is Prof. KC Kim. Mr. Baral received his bachelor and master degree in mechanical engineering from Institute of Engineering, Pulchowk Campus and Kathmandu University, Nepal respectively. $\mathrm{He}$ is a permanent faculty member in Pokhara University, Nepal as a lecturer. His areas of research interests are renewable energy and energy conversion technology.

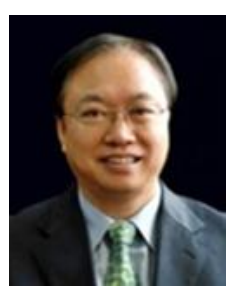

Kyung Chun Kim is a professor in the School of Mechanical Engineering of Pusan National University in Korea. He obtained the Ph.D. degree from the Korea Advanced Institute of Science and Technology (KAIST), Korea, in 1987. He was selected as a member of the National Academy of Engineering of Korea in 2004. His research interests include 3D3C Micro-PIV, Bio-MEMS, turbulent flow measurements based on PIV/LIF, biomedical engineering, POCT development, wind turbines, and organic Rankine cycle system. 